\title{
Novedades en la web de enero a mayo de 2005
}

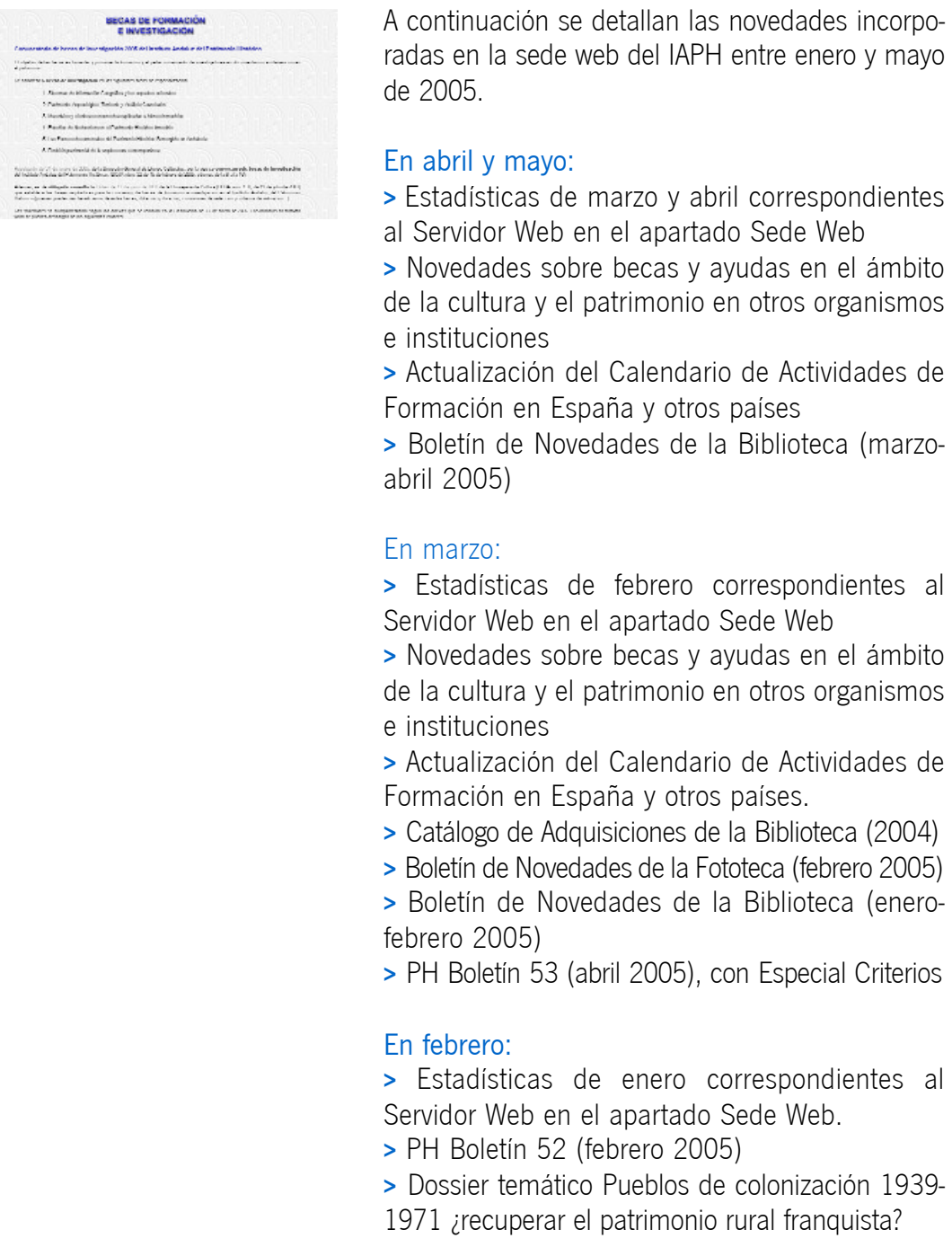

$>$ Convocatoria de becas de investigación del IAPH 2005

> Novedades sobre becas y ayudas en el ámbito de la cultura y el patrimonio en otros organismos e instituciones

$>$ Actualización del Calendario de Actividades de Formación en España y otros países

> Boletín de Novedades de la Biblioteca (octubre 2004-enero 2005)

> Actualización cuentas de correo-e. del IAPH

En enero:

$>$ Estadisticas de diciembre correspondientes al Servidor Web en el apartado Sede Web

$>$ Estadisticas anuales del Servidor Web y de Novedades de Información del PH en Servicios de Información

> Actualización de la información de Cifras en el apartado Sede Web: fechas destacadas en la implantación de otros productos y servicios y datos estadisticos relevantes

$>$ PH Boletín 51(octubre 2004)

$>$ Novedades sobre becas y ayudas en el ámbito de la cultura y el patrimonio en otros organismos e instituciones

$>$ Actualización del Calendario de Actividades de Formación en España y otros países

$>$ Actualización de los másters y posgrados de Patrimonio y Gestión Cultural en España $2004 / 2005$

Susana Limón Rodríguez

Centro de Documentación del IAPH

\section{¿Quieres opinar sobre patrimonio y cine?}

El próximo número monográfico de PH Boletín del IAPH, $n^{\circ} 56$ (diciembre 2005), estará dedicado a las relaciones existentes entre patrimonio cultural y cine. Este Debate e Investigación ofrecerá una reflexión sobre el valor del cine como patrimonio histórico/cultural, al mismo tiempo que pondrá de manifiesto los vínculos del cine con la sociedad.

Si deseas participar en la sección Opinión del Lector de este número, las siguientes preguntas pueden orientarte en tu comentario:

1. ¿Ha de gozar el cine de la misma consideración y protección que los bienes culturales clásicos? ¿Por qué?

2. ¿Qué aporta la cinematografia al patrimonio cultural español y europeo?

3. ¿Qué relaciones pueden establecerse entre la cinematografia y las disciplinas vinculadas al patrimonio cultural (Arquitectura, Antropologia, Bellas Artes, Geografia, Arqueologia, Documentación, etc.)?

El texto, no superior a 1 DIN A4 (tipo arial 10, interlineado 1 '5), deberá ser enviado antes del 1 de octubre de 2005, a la dirección boletin.iaph.ccul@juntadeandalucia.es 